\title{
Implementation of infection control in health facilities in Arua district, Uganda: a cross-sectional study
}

Peter Wasswa ${ }^{1 *}$, Christine K. Nalwadda ${ }^{2}$, Esther Buregyeya ${ }^{2}$, Sheba N. Gitta ${ }^{1}$, Patrick Anguzu ${ }^{3}$ and Fred Nuwaha ${ }^{2}$

\begin{abstract}
Background: At least 1.4 million people are affected globally by nosocomial infections at any one time, the vast majority of these occurring in low-income countries. Most of these infections can be prevented by adopting inexpensive infection prevention and control measures such as hand washing. We assessed the implementation of infection control in health facilities and determined predictors of hand washing among healthcare workers (HCWs) in Arua district, Uganda.

Methods: We interviewed $202 \mathrm{HCW}$ s that included 186 randomly selected and 16 purposively selected key informants in this cross-sectional study. We also conducted observations in 32 health facilities for compliance with infection control measures and availability of relevant supplies for their implementation. Quantitative data underwent descriptive analysis and multiple logistic regressions at $95 \%$ confidence interval while qualitative data was coded and thematically analysed.

Results: Most respondents (95/186, $51 \%$ ) were aware of at least six of the eight major infection control measures assessed. Most facilities (93.8\%, 30/32) lacked infection control committees and adequate supplies or equipment for infection control. Respondents were more likely to wash their hands if they had prior training on infection control $(\mathrm{AOR}=2.71,95 \% \mathrm{Cl}:$ 1.03-7.16), had obtained at least 11 years of formal education ( $\mathrm{AOR}=3.30,95 \% \mathrm{Cl}: 1.44-7.54)$ and had reported to have acquired a nosocomial infection (AOR $=2.84,95 \% \mathrm{Cl}: 1.03-7.84)$.

Conclusions: Healthcare workers are more likely to wash their hands if they have ever suffered from a nosocomial infection, received in-service training on infection control, were educated beyond ordinary level, or knew hand washing as one of the infection control measures. The Uganda Ministry of Health should provide regular in-service training in infection control measures and adequate necessary materials.
\end{abstract}

Keywords: Infection control, Implementation, Health facilities, Hand washing, Healthcare workers, Uganda

\section{Background}

The World Health Organization (WHO) estimates that over 1.4 million people suffer from nosocomial infections at any one time, with the proportion of these infections being up to 20 times higher in low and middle income countries [1]. These infections are among the leading cause of death and morbidity among hospitalized patients and present a considerable public health burden [2].

Although there is limited data on nosocomial infections in Sub-Saharan Africa, several studies done in Algeria, Burkina Faso, Senegal and Tanzania have indicated

\footnotetext{
* Correspondence: pwasswa@afenet.net

'African Field Epidemiology Network, Kampala, Uganda

Full list of author information is available at the end of the article
}

hospital-wide prevalence rates ranging from $2.5 \%$ to $14.8 \%$ [3-6]. Higher cumulative incidence rates have been reported in surgical wards in Ethiopia and Nigeria ranging from $5.7-45.8 \%[7,8]$. In developing countries, a growing proportion of nosocomial infections can be assigned to methicillin-resistant S. aureus (MRSA) and multi-drug resistant Gram-negative bacteria [9, 10]. A survey done in an Argentinean general hospital revealed incidence rates of Clostridium difficile, the commonest cause of nosocomial infectious diarrhoea to range from 37 to 84 cases per 10,000 admissions between 2000 and 2005 while the annual incidence of the same infection was 8.7 cases/10 000 hospitalisations in a study done in South Africa [11, 12].

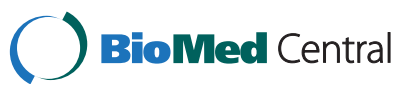

(C) 2015 Wasswa et al. This is an Open Access article distributed under the terms of the Creative Commons Attribution License (http://creativecommons.org/licenses/by/4.0), which permits unrestricted use, distribution, and reproduction in any medium, provided the original work is properly credited. The Creative Commons Public Domain Dedication waiver (http:// creativecommons.org/publicdomain/zero/1.0/) applies to the data made available in this article, unless otherwise stated. 
Most nosocomial infections can be prevented with readily available and inexpensive strategies like adhering to recommended infection control measures such as hand hygiene and wearing of gloves [2]. Globally, standard precautions of infection control are considered an effective means of protecting healthcare workers, patients and the public and reducing nosocomial infections [13, 14]. A meta-analysis by Aiello and Larson indicated that appropriate hand hygiene practices significantly reduced the risk of nosocomial infections while a case-control study conducted in Brazil singled-out poor hand hygiene in addition to overcrowding and understaffing as risk factors for nosocomial infections $[15,16]$.

A number of factors may influence adherence to infection control. A healthcare worker was more likely to be compliant if he/she had more experience on the job, was more knowledgeable about transmission of blood-borne pathogens and was strongly committed to a positive occupational safety climate [17]. A descriptive exploratory study conducted in Botswana amongst emergency department nurses identified resource constraints such as the lack of the necessary facilities, inadequate equipment and materials, inadequate staffing and the lack of sustainable in-service education as factors that could prevent them from complying with infection control measures [18].

Several studies conducted amongst doctors and nurses in Ethiopia, Nigeria, Thailand and Uganda concluded that the knowledge, understanding and interpretation of infection control measures are not adequate. This as a result adversely affected the implementation of the measures [19-22]. Although knowledge of standard precautions of infection control may improve adherence to the measures, other influencing factors which this study was not able to investigate such as attitude are equally important [21].

In Uganda, the Ministry of Health $(\mathrm{MOH})$ lists five basic standard precaution measures that can enhance infection control within the health facilities. These are: hand hygiene, adequate protective wear, proper sterilization, proper sharps disposal and safe waste management [23]. However, findings from a national service provision assessment survey conducted by $\mathrm{MOH}$ showed that only $6 \%$ of health facilities had all infection control items while supervisory visits to health facilities in Arua District in 2006 revealed that less than $60 \%$ of the assessed facilities implemented the required infection control measures [24].

We assessed the implementation of infection control in health facilities in Arua district and determined the predictors of hand washing among healthcare workers.

\section{Methods}

\section{Study design and setting}

We conducted a health facility-based cross-sectional study in Arua district, Uganda in 2008. Arua is located about $530 \mathrm{~km}$ northwest of Kampala City bordering the Democratic Republic of Congo (DRC). The district had a projected mid-2007 population of about 500,000 people, $23 \%$ of which were less than five years old [25]. There were 36 government health facilities, five private-not-for profit (PNFP) health facilities and 17 private health clinics in the district.

\section{Sample size determination}

The formula for survey sampling by Leslie Kish was used to determine the number of healthcare workers selected for the study, where; $p=0.48$ (estimated prevalence of health workers who wash their hands [26, 27]. The level of precision was 0.05 and confidence interval at $95 \%$ give a sample size of 384 respondents. However, because Arua had an estimated total of 360 healthcare workers, fewer than the computed sample size of 384 respondents, Cochran's correction formula was employed to get the final sample size of 186 respondents [28].

\section{Sampling procedure}

We used two sampling methods to select the health facilities. Simple random sampling was used to select the lower level health units (Clinics, Health Centre (HC) II and $\mathrm{HC}$ III) while purposive sampling was used to select the higher level health units (both hospitals and all three HCIVs). The latter method was used in order to avoid excluding the higher level units since they performed major operations such as caesarean sections which were more likely to expose patients and health care workers (HCWs) to nosocomial infections. Using the fish-bowl technique and sampling without replacement, we randomly selected 10 out of the 12 HC IIIs in the district, 9 out of the 17 private clinics and 8 out of the $25 \mathrm{HC}$ IIs. The number of healthcare workers obtained from each $\mathrm{HC}$ level was arrived at using probability proportionateto-size sampling in an approximate ratio of 5: 1: 2: 1: 1 for hospitals, HCIVs, HCIIIs, HCIIs and private clinics respectively since the units were estimated to have 150 , 40, 75, 50 and 50 staff respectively.

Using the list of the HCWs in each facility as the sampling frame, we selected the respondents from each health facility by simple random sampling, again adopting the fish bowl technique and sampling without replacement making sure that HCWs were sampled from all the available sections in that facility where possible. Sixteen key informants who were senior nursing officers, heads of infection control committees or health facility heads were purposively sampled from $50 \%(16 / 32)$ of the health facilities that were randomly selected. All respondents who were approached for the quantitative data consented to be interviewed while one key informant who had been selected was not 
available during the data collection stage and was later replaced by his deputy.

\section{Eligibility criteria}

All healthcare workers in Arua district working in the selected health facilities at the time of the study and provided written informed consent were eligible. Any health workers not present during the data collection period were excluded from the study.

\section{Study variables}

Washing of hands before conducting aseptic procedures was the primary dependent variable. Other secondary dependent variables assessed were wearing of gloves before conducting aseptic procedures, disposal of used sharps, disposal of waste, isolation of patients and cleaning of the health facilities. The independent variables included age, sex, in-service training (number of times they had received formal training on infection control in the last five years), qualification of healthcare worker, ownership of health facility (private or government) and knowledge of infection control measures. Knowledge was assessed by determining how many of the eight major infection control measures as described by WHO [2] In table below were mentioned by the HCWs.

Description of infection control measures that were assessed during the study are described in Fig. 1.
A scoring criterion of poor, fair, good and excellent adapted from Suchitra et al. [29] was used if a HCW mentioned 1-2, 3-4, 5-6 and 7-8 numbers of the measures respectively.

\section{Data collection}

We interviewed HCWs using a structured questionnaire and key informants using a key informant guide (Additional file 1). The former tool was administered to the HCWs to obtain information about knowledge and practices on infection control and their responses were filled in by the data collectors while the latter tool was used to assess availability of infection control resources and capacity to monitor nosocomial infections (Additional file 1). Specific health facility sections such as injection and dressing rooms, examination rooms, laboratory and maternity wards were also observed for compliance with infection control and availability of enabling supplies such as water, soap, personal protective wear and waste disposal bins using a checklist. To ensure data quality, a team of three data collectors were trained on how to conduct the interviews and inconspicuously observe the HCWs for hand washing in $30 \mathrm{~min}$ intervals. The data collectors focused their observations on the five key moments recommended by WHO when HCWs should wash their hands: before patient contact, before an aseptic procedure, following exposure to bodily fluid, following patient contact,

\begin{tabular}{|l|l|}
\hline Measure & Description \\
\hline Hand washing & Washing hands with plain or antimicrobial soap and water \\
\hline Personal protective wear & $\begin{array}{l}\text { Specialised clothing or equipment worn by an employee for } \\
\text { protection against infectious materials }\end{array}$ \\
\hline $\begin{array}{l}\text { Safe medical waste } \\
\text { disposal }\end{array}$ & $\begin{array}{l}\text { Removal of all potentially contaminated objects and placement } \\
\text { in a secure site to prevent or decrease the risk of infection }\end{array}$ \\
\hline Isolation & $\begin{array}{l}\text { Measures taken to prevent infectious diseases from being } \\
\text { spread between patients, healthcare workers and visitors }\end{array}$ \\
\hline Disinfection & $\begin{array}{l}\text { A process that eliminates all pathogenic microorganisms, with } \\
\text { the exception of bacterial spores }\end{array}$ \\
\hline Sterilisation & $\begin{array}{l}\text { The complete destruction of all forms of microbial life, } \\
\text { including bacteria, viruses, and spores }\end{array}$ \\
\hline Housekeeping & $\begin{array}{l}\text { The routine cleaning of all surfaces so as to maintain a high } \\
\text { level of hygiene in the health facility }\end{array}$ \\
\hline Injection safety & $\begin{array}{l}\text { Safe injection is an injection that does no harm to the recipient, } \\
\text { does not expose the health worker to any risk and does not } \\
\text { result in waste that puts the community at risk }\end{array}$ \\
\hline
\end{tabular}

Fig. 1 Description of infection control measures that were assessed during the study 
and after contact with patient surroundings [30]. The questionnaires were pre-tested in two non-participating private health clinics. Data were checked for completeness before the data collectors left the field.

\section{Data management and analysis}

Quantitative data underwent descriptive analysis and multiple logistic regressions at $95 \%$ confidence interval (CI). The data were first entered into an Epi info version 3.4.3 database and cleaned, cross-checked and then exported to STATA, version 10 software for analysis. For continuous variables, mean (SD) and median (range) were calculated while for categorical variables, proportions were used. Our primary dependent variable was washing of hands during the five key moments as recommended by WHO. Pearson chi-square test or Fisher's exact test were used when appropriate in bivariate analysis. Multivariate backwards stepwise logistic regression analysis was performed to identify predictors of hand washing. All variables significant during bivariate analysis at a $p$-value $\leq 0.1$ were introduced in the regression model to obtain the adjusted odds ratio (AOR) of each factor on the primary dependent variable at $95 \%$ confidence interval. Qualitative data was analysed through manifest content analysis with the aid of Microsoft Excel. We read through the recorded transcripts and coded the responses. The codes were then grouped into related categories and then into emerging themes and subthemes. The main themes were capacity of the health facilities to monitor hospital-acquired infections and availability of resources to implement infection control measures. Picking responses from the themes, we used representative quotes to summarise our key findings.

\section{Ethical considerations}

Ethical review and approval was sought from the Uganda National Council of Science and Technology through Makerere University School of Public Health Higher Degrees Research and Ethics Committee. The District Health Officers (DHOs) as well as the heads of the selected health facilities were contacted for their permission before data were collected. Written informed consent was obtained from all the respondents prior to the conduct of the interviews. Confidentially was observed and the respondents' right to withdraw from the study without any repercussions on their work was emphasised.

\section{Results}

\section{Questionnaire findings}

Socio-demographic characteristics of the

healthcare workers

The mean (SD) age of the $186 \mathrm{HCWs}$ was 36.3 (8.9) years and median (range) age was $35.0(22-59)$ years.
The average time spent working in the health service was 11.9 (SD 8.8) years. Nearly all of the respondents ( $98.9 \%$, 184/186) had attained at least ordinary level education (11 years of formal education) as shown in Table 1.

\section{Knowledge of infection control measures}

Most HCWs $(51.1 \%, 95 / 186)$ mentioned at least six of the eight major infection control measures we assessed while only $47.8 \%(89 / 186)$ and $17.2 \%(32 / 186)$ cited housekeeping and isolation respectively. Slightly over half of the respondents $(51.4 \%, 95 / 186)$ had ever read the Uganda Ministry of Health guidelines on infection control and only $43.5 \%$, (81/186) said they always followed them although this could not be verified. Most of the respondents $(72.6 \%, 135 / 186)$ said they had never had any in-service training on infection

Table 1 Socio-demographic characteristics of the healthcare workers interviewed on infection control in Arua district, 2008

\begin{tabular}{|c|c|c|}
\hline Characteristic & $\begin{array}{l}\text { Frequency } \\
N=186\end{array}$ & Percent \\
\hline \multicolumn{3}{|l|}{ Age group (Years) } \\
\hline $20-29$ & 45 & $24.2 \%$ \\
\hline $30-39$ & 83 & $44.6 \%$ \\
\hline $40-49$ & 39 & $21.0 \%$ \\
\hline $50-59$ & 19 & $10.2 \%$ \\
\hline \multicolumn{3}{|l|}{ Sex } \\
\hline Male & 85 & $45.7 \%$ \\
\hline Female & 101 & $54.3 \%$ \\
\hline \multicolumn{3}{|l|}{ Highest education level } \\
\hline Primary ( $\geq 7$ years formal education) & 2 & $1.1 \%$ \\
\hline Ordinary level ( $\geq 11$ years of formal education) & 98 & $52.7 \%$ \\
\hline Advanced level/ tertiary & 86 & $46.3 \%$ \\
\hline \multicolumn{3}{|l|}{ Qualification } \\
\hline Nursing Assistant & 40 & $21.5 \%$ \\
\hline Enrolled Nurse & 38 & $20.4 \%$ \\
\hline Registered Nurse & 33 & $17.7 \%$ \\
\hline Enrolled Midwife & 18 & $9.7 \%$ \\
\hline Clinical Officer & 15 & $8.1 \%$ \\
\hline Laboratory Assistant & 14 & $7.5 \%$ \\
\hline Registered Midwife & 13 & $7.0 \%$ \\
\hline Others & 15 & $8.1 \%$ \\
\hline \multicolumn{3}{|l|}{ Years in service } \\
\hline $0-9$ & 88 & $47.3 \%$ \\
\hline $10-19$ & 62 & $33.3 \%$ \\
\hline $20-29$ & 24 & $12.9 \%$ \\
\hline$>30$ & 12 & $6.5 \%$ \\
\hline
\end{tabular}


control, a finding which was corroborated by the key informants.

\section{Findings from key informants \\ Theme: capacity of the health units to monitor hospital-acquired infections}

Most of the key informants reported lack of specific structures to promote infection control activities within the health facilities, contrary to what was in the $\mathrm{MOH}$ guidelines.

'We do not have committees or any structure to monitor for those infections that may be got from our health facility. However, we suspect that some infections may be acquired from poorly done surgeries at times.' (Medical Officer)

"For instance, when there is post-operative sepsis, we investigate where it is coming from. In February this year, we had at least three cases of post-operative sepsis in maternity". (Hospital Key informant)

\section{Theme: availability of supplies to implement infection control measures}

Stock outs were a relatively common occurrence as confirmed by most key informants. All government run health facilities reported to routinely experience some form of shortage of supplies essential for infection control during the past year. The most commonly inadequate supplies were gloves, disinfectants and soap. Whereas most stock-outs lasted about 1-2 weeks, some lasted for up to three months.

In April, we run out of syringes and gloves for about 2 weeks. We therefore told the patients to go and buy their own supplies. (Senior Nursing Officer)

Conversely, unlike government facilities, key informants from private facilities did not report any stock outs of infection control supplies.

\section{Theme: capacity of healthcare workers to implement infection control measures}

The key informants from both public and private hospitals mentioned that the health facilities were grossly understaffed, with the latter reportedly operating with only about $50 \%$ of the expected number of healthcare staff. Likewise, remote facilities also had a significant shortage of staff. However, two health facilities in Arua municipality were over-staffed.
"The person responsible for infection control is a registered nurse who was sent for training."

(HCIV Key informant)

Most of the 16 key informants interviewed mentioned that they did provide regular in-service training on infection control to $\mathrm{HCWs}$ in their respective facilities. In most instances, all that was done were occasional reminders from the medical doctors or senior nurses about the need to implement infection control measures.

'We occasionally remind our staff about maintaining hygiene but this is general and not specific to infection control' (Senior Nursing Officer)

\section{Checklist results}

\section{Observation of infection control measures}

Hand washing was practiced by $74.7 \%(139 / 186)$ of the health workers observed during any of the five key moments recommended by WHO while two-thirds $(124 / 186)$ wore gloves when appropriate. Isolation was observed in only $6.3 \%(2 / 32)$ of the health facilities while disposal of sharps in suitable containers (90.6\%, 29/32) was the most commonly observed practice. Recapping of needles $(34.4 \%, 11 / 32)$ was the least observed practice (Table 2). While most facilities (59.4\% 19/32) lacked functional placenta pits, the majority of the injection and dressing rooms (75 \%, 18/24), were relatively clean, having no litter or significant amounts of bio hazardous waste on the operating tables or floors.

\section{Availability of supplies needed for infection control}

All the health facilities were observed for the necessary supplies needed to implement infection control measures. The most available item was running water

Table 2 Observation of infection control in health facilities in Arua district, 2008

\begin{tabular}{lll}
\hline Activity & $\begin{array}{l}\text { Frequency } \\
(\%)\end{array}$ & $\begin{array}{l}\text { Total } \\
\text { N }\end{array}$ \\
\hline All needles not recapped after use & $11(34.4)$ & 32 \\
Needles disposed in suitable containers & $29(90.6)$ & 32 \\
Placed sharp and non-sharp waste in separate & $30(93.8)$ & 32 \\
bins & & \\
Sections below adequately clean & & \\
Injection / dressing & $24(75.0)$ & 32 \\
Examination/ consultation & $21(80.8)$ & $26^{\mathrm{b}}$ \\
Laboratory & $18(90.0)$ & $20^{\mathrm{b}}$ \\
Maternity & $12(75.0)$ & $16^{\mathrm{b}}$ \\
\hline
\end{tabular}

${ }^{a}$ No visible presence of blood, or any potentially infectious contaminated waste material such as used cotton, sharps or gloves on the operating table or floors ${ }^{\mathrm{b}}$ Sections not available in these facilities 
(90.4 \%, 29/32), while the least available items were alcohol hand rubs $(3.1 \%, 1 / 32)$ and protective eye wear $(6.3 \%, 2 / 32)$ as summarised in the Table 3. Medical waste was indiscriminately disposed in all observed facilities, with sharps frequently mixed with other waste at the final rubbish dumps.

\section{Predictors of hand washing}

HCWs who had received in-service training on infection control (AOR 2.71, CI: 1.03-7.16), were educated beyond ordinary level (AOR 3.30, CI: 1.44-7.54), mentioned hand washing as one of the infection control measures they knew (AOR 5.70, 2.64-12.32) or those who reported to have acquired a nosocomial infection (AOR 2.84, 1.03-7.84) were more likely to wash their hands than their colleagues without these attributes. The qualification of the HCWs which was significant at bivariate level was not significant at this multivariate level of analysis (Table 4).

\section{Discussion}

We sought to assess the level of implementation of infection control measures in rural Uganda and factors influencing this implementation. We found that most HCWs washed their hands and used gloves when the circumstances required so and that most of them were generally knowledgeable about the different infection

Table 3 Availability of infection control supplies in health facilities in Arua district, 2008

\begin{tabular}{llcl}
\hline Supply & Frequency (Yes) & Percent & Total N \\
\hline Hand rubs & 1 & 3.1 & 32 \\
Protective eye wear & 2 & 6.3 & 32 \\
Safety signs for hazardous wastes & 6 & 18.8 & 32 \\
Face masks & 11 & 34.4 & 32 \\
Functional placenta pit & 13 & 40.6 & 32 \\
Containers with secure lids & 14 & 43.8 & 32 \\
Gowns/aprons & 16 & 50.0 & 32 \\
Functional autoclave & 16 & 50.0 & 32 \\
Waste pit & 18 & 56.3 & 32 \\
Soap & 22 & 68.8 & 32 \\
Auto-destruct syringes & 23 & 71.9 & 32 \\
Pit latrine & & & \\
Functional & 25 & 78.1 & 32 \\
Clean & 11 & 44.0 & 25 \\
Ordinary single-use syringes & 26 & 81.3 & 32 \\
Disposable gloves & 27 & 84.4 & 32 \\
Sharps disposal containers & 27 & 84.4 & 32 \\
Water & 29 & 90.6 & 32 \\
Waste pit contain sharps & 18 & 100 & 18 \\
\hline
\end{tabular}

control measures. Infection control supplies were generally inadequate, notably soap and personal protective wear. We found that HCWs who had received inservice training on infection control, those that were educated beyond ordinary level, those who cited hand washing as one of the infection control measures, and the ones that reported to have suffered from a nosocomial infection were more likely to wash their hands than their counter parts.

We found a higher level of hand washing than has been reported in several studies [31-34]. This may be probably because most of the observed HCWs were nurses. Numerous studies have shown nurses are more likely to wash their hands compared to doctors and nursing assistants [35-38]. It is also possible that some of the HCWs were aware they were being observed especially since many of them were also interviewed about the same subject later on.

Adequate knowledge was also strongly associated with hand washing. Similarly, Askarian et al. found that nurses with adequate knowledge where 14 times more likely to comply with the eight universal precaution measures that the authors assessed [39].

Gloves were the most worn protective gear. This is probably because gloves are relatively affordable compared to other personal protective wear such as gowns. Furthermore, virtually all categories of HCWs need them at some point during their work unlike other specialised wear such as goggles and masks which are more commonly used for non-routine activities such as isolation and major surgeries [40].

The considerably high levels of needle recapping observed at the health facilities (34.4\%) are comparable to those of a cross-sectional study by Sadoh et al. where $31.9 \%$ of the HCWs always recapped needles [41]. This finding could be as a result of the lack of clear guidelines on needle recapping. It could also be that many HCWs do not perceive the risks of this practice.

The inadequate number of HCWs who always followed the guidelines may be partially attributed to the low percentage of respondents that had ever read the guidelines. Another reason may be because of the low number HCWs that had ever received in-service training on infection control. Indeed, multivariate analysis showed that HCWs were more likely to wash their hands if they had ever had received training on infection control, a finding that was also observed in the Keren Hospital study [42].

Most of the health facilities had water in at least one of the sections observed. This differed significantly from the service provision survey conducted by the Uganda Ministry of Health and Macro International Inc. which found that only $43 \%$ of the maternal and child health facilities had running water. The same study found that 
Table 4 Predictors of hand washing and among healthcare workers in Arua district, 2008

\begin{tabular}{|c|c|c|c|c|c|c|c|}
\hline \multirow[b]{2}{*}{ Factor } & \multirow[b]{2}{*}{ Category } & \multicolumn{3}{|c|}{ Hand washing } & \multirow[b]{2}{*}{$P$-Value } & \multirow[b]{2}{*}{$\begin{array}{l}\text { Adjusted OR } \\
(95 \% \mathrm{Cl})\end{array}$} & \multirow[b]{2}{*}{$P$-Value } \\
\hline & & Yes (\%) & No (\%) & $\begin{array}{l}\text { Crude OR } \\
(95 \% \mathrm{Cl})\end{array}$ & & & \\
\hline \multirow[t]{2}{*}{ Received in-service training $(n=186)$} & Yes & $44(86)$ & $7(14)$ & $2.65(1.06-7.53)$ & $0.036^{*}$ & $2.71(1.03-7.16)$ & $0.045^{*}$ \\
\hline & No & $95(70)$ & $40(30)$ & 1.00 & & & \\
\hline \multirow[t]{2}{*}{ Read guidelines $(n=185)$} & Yes & $72(76)$ & $23(24)$ & $1.14(0.56-2.33)$ & 0.738 & $0.71(0.32-1.59)$ & 0.409 \\
\hline & No & $66(73)$ & $24(27)$ & 1.00 & & & \\
\hline \multirow[t]{2}{*}{ Can explain infection control $(n=184)$} & Yes & $126(77)$ & $37(23)$ & $2.56(0.87-7.16)$ & 0.060 & $1.63(0.54-4.90)$ & 0.379 \\
\hline & No & $12(57)$ & $9(43)$ & 1.00 & & & \\
\hline \multirow[t]{2}{*}{ Educated beyond O 'level $(n=186)$} & Yes & $74(86)$ & $12(14)$ & $3.32(1.52-7.59)$ & $0.001^{*}$ & $3.30(1.44-7.54)$ & $0.005^{*}$ \\
\hline & No & $65(65)$ & $35(35)$ & 1.00 & & & \\
\hline \multirow[t]{2}{*}{$<35$ years $(n=186)$} & Yes & $67(76)$ & $21(24)$ & $1.15(0.56-2.37)$ & 0.737 & $0.68(0.22-2.07)$ & 0.497 \\
\hline & No & $72(73)$ & $26(27)$ & 1.00 & & & \\
\hline \multirow[t]{2}{*}{$\operatorname{Sex}(n=186)$} & Female & $78(77)$ & $23(23)$ & $1.33(0.65-2.73)$ & 0.403 & $0.88(0.37-2.13)$ & 0.785 \\
\hline & Male & $24(28)$ & $61(72)$ & 1.00 & & & \\
\hline \multirow{2}{*}{$\begin{array}{l}\text { Cites hand washing as one of infection } \\
\text { control measures known }(n=186)\end{array}$} & Yes & $107(86)$ & $17(14)$ & $5.90(2.73-12.87)$ & $<0.001^{*}$ & $5.70(2.64-12.32)$ & $0.000^{*}$ \\
\hline & No & $32(52)$ & $30(48)$ & 1.00 & & & \\
\hline \multirow{2}{*}{$\begin{array}{l}\text { Has ever acquired a nosocomial infection } \\
(n=186)\end{array}$} & Yes & $32(82)$ & $7(18)$ & $1.71(0.67-4.95)$ & 0.302 & $2.84(1.03-7.84)$ & $0.043^{*}$ \\
\hline & No & $107(73)$ & $40(27)$ & 1.00 & & & \\
\hline \multirow[t]{2}{*}{ Qualified beyond nursing assistant $(n=186)$} & Yes & $101(81)$ & $23(19)$ & $2.77(1.17-5.13)^{*}$ & $0.004^{*}$ & $1.71(0.72-4.06)$ & 0.223 \\
\hline & No & $38(61)$ & $24(39)$ & 1.00 & & & \\
\hline \multirow{2}{*}{$\begin{array}{l}\text { Healthcare worker from government } \\
\text { (public) health facility }(n=186)\end{array}$} & Yes & $86(78)$ & $24(22)$ & $1.56(0.75-3.19)$ & & & \\
\hline & No & $53(70)$ & $23(30)$ & 1.00 & 0.058 & $2.19(0.96-4.97)$ & 0.061 \\
\hline
\end{tabular}

*statistically significant at $p=0.05$

only $56 \%$ of the health facilities had sharps disposal containers compared to $84.4 \%$ of the facilities in this study. These differences may be as a result of the much larger sample size $(n=491)$ for the nationwide survey, regional variations but also because they could been recently procured [24].

Some of the supplies like waste and placenta pits were not available in many facilities probably because they were not that necessary for the level of operations of such facilities or there was limited space to accommodate them. In some situations, some of these facilities were incompatible with the surrounding environment, especially the private clinics in the municipalities.

We found that HCWs who had had prior in-service training were more likely to wash their hands. Indeed, several studies have shown that in-service training enhances compliance with infection control measures [43-46]. Regular training helps to remind the health workers of the importance of these measures.

The results of this study should be interpreted in light of some limitations. It was not possible to observe all sections within each facility which may not have given a comprehensive picture of the infection control compliance. Hence, some observations such as recapping of needles were done by proxy by looking through the waste bins. Staff in a few lower health centres were absent on the data collection days and hence only observations were made in these facilities. We could not verify whether health workers who stated they always followed the infection control guidelines did so due to the limited amount of time of observation. Lastly, some HCWs may have been aware that we were being observed despite measures taken to be discreet, and so this may have resulted in a relatively high level of hand washing compliance found.

\section{Conclusion}

Healthcare workers were fairly knowledgeable about most infection control measures with the exception of isolation and housekeeping. Isolation, the use of personal protective wear and avoiding of needle recapping were inadequately implemented. There were insufficient infection control supplies in most of the health facilities which may have limited the implementation of infection control measures. Healthcare workers are more likely to wash their hands if they have ever 
received in-service training on infection control, are educated beyond ordinary level, report that they have ever acquired a nosocomial infection or state hand washing as one of the infection control measures they know.

Based on the findings of this study, we recommend that respective health facilities should provide continuous education and training on infection control to all staff. The ministry of health through the district health office should also provide adequate infection control supplies.

\section{Additional file}

Additional file 1: Tools used to collect data on infection control implementation in health facilities in Arua District, 2008.

\section{Abbreviations}

CKN: Christine Kayemba Nalwadda; EB: Esther Buregyeya; FN: Fred Nuwaha; PA: Patrick Anguzu; PW: Peter Wasswa; SNG: Sheba Nacacubo Gitta.

\section{Competing interests}

The authors declare that they have no competing interests.

\section{Authors' contributions}

CKN: Conception, design, data analysis and interpretation, critical review and approval of final version. EB: Conception, design, data analysis and interpretation, critical review and approval of final version. FN: Conception, design, data analysis and interpretation, critical review and approval of final version. PA: Conception, design, data analysis and interpretation, critical review and approval of final version. PW: Conception, design, data analysis and interpretation, critical review and approval of final version. SNG: Data analysis and interpretation, critical review and approval of final version. All authors read and approved the final manuscript.

\section{Acknowledgements}

The authors thank the Mr Richard Onzima, the Arua District TB and Leprosy Focal Person who provided guidance in selection of the health facilities and assisted in data collection. We also recognise the efforts of Mr Mutebi Aloysius and Mr Mulumba Yusuf who provided advice during data analysis. The authors declare that there were no external sources of funding for this study and all costs incurred were self-sponsored.

\section{Author details}

${ }^{1}$ African Field Epidemiology Network, Kampala, Uganda. ${ }^{2}$ School of Public Health, Makerere University College of Health Sciences, Kampala, Uganda.

${ }^{3}$ Arua District Health Office, Arua, Uganda.

Received: 5 September 2014 Accepted: 25 June 2015

Published online: 14 July 2015

\section{References}

1. Pittet $D$, Donaldson L. Clean care is safer care: the first global challenge of the WHO world alliance for patient safety. Infect Control Hosp Epidemiol. 2005;26(11):891-4

2. Ducel G, Fabry J, Nicole L, editors. Prevention of hospital -acquired infections,- a practical field guide. WHO Department of Communicable Disease and Surveillance. 2nd ed. 2002. http://www.who.int/csr/resources/ publications/drugresist/en/whocdscsreph200212.pdf.

3. Atif ML, Bezzaoucha A, Mesbah S, Djellato S, Boubechou N, Bellouni R. [Evolution of nosocomial infection prevalence in an Algeria university hospital (2001 to 2005)]. Med Mal Infect. 2006;36((8):423-8.

4. Lamarque D. Prevalence of nosocomial infections in a pediatric hospital in Ouagadougou. Med Trop (Mars). 2003;63(6):636-7.
5. Dia NM, Ka R, Dieng C, Diagne R, Dia ML, Fortes $L$, et al. Prevalence of nosocomial infections in a university hospital (Dakar, Senegal). Med Mal Infect. 2008;38(5):270-4.

6. Gosling R, Mbatia R, Savage A, Mulligan JA, Reyburn H. Prevalence of hospital-acquired infections in a tertiary referral hospital in northern Tanzania. Ann Trop Med Parasitol. 2003:97(1):69-73.

7. Messele G, Woldemedhin Y, Demissie M, Mamo K, Geyid A. Common causes of nosocomial infections and their susceptibility patterns in two hospitals in Addis Ababa. Ethiop J Health Biomed Sci. 2009;2:3-8.

8. Kesah CN, Egri-Okwaji MT, Iroha E, Odugbemi TO. Aerobic bacterial nosocomial infections in paediatric surgical patients at a tertiary health institution in Lagos, Nigeria. Niger Postgrad Med J. 2004;11(1):4-9.

9. Rosenthal VD, Guzman S, Crnich C. Device-associated nosocomial infection rates in intensive care units of Argentina. Infect Control Hosp Epidemiol. 2004;25(3):251-5.

10. Fehr J, Hatz C, Soka I, Kibatala P, Urassa H, Smith T, et al. Risk factors for surgical site infection in a Tanzanian district hospital: a challenge for the traditional National Nosocomial Infections Surveillance system index. Infect Control Hosp Epidemiol. 2006;27(12):1401-4.

11. Goorhuis A, Legaria MC, Van Den Berg RJ, Harmanus C, Klaassen CH, Brazier JS, et al. Application of multiple-locus variable-number tandem-repeat analysis to determine clonal spread of toxin A-negative clostridium difficile in a general hospital in Buenos Aires, Argentina. Clin Microbiol Infect. 2009;15(12):1080-6.

12. Rajabally NM, Pentecost M, Pretorius G, Whitelaw A, Mendelson M, Watermeyer $\mathrm{G}$. The clostridium difficile problem: a South African tertiary institution's prospective perspective. S Afr Med J. 2013;103(3):168-72.

13. Roberts $\mathrm{C}$. Universal precautions: improving the knowledge of trained nurses. Br J Nurs. 2000;9(1):43-7

14. Wang $H$, Fennie $K$, He G, Burgess J, Williams AB. A training programme for prevention of occupational exposure to bloodborne pathogens: impact on knowledge, behaviour and incidence of needle stick injuries among student nurses in Changsha, People's Republic of China. J Adv Nurs. 2003;41(2):187-94

15. Aiello AE, Larson EL. What is the evidence for a causal link between hygiene and infections? Lancet Infect Dis. 2002;2(2):103-10.

16. Pessoa-Silva CL, Meurer MB, Camara AV, Flannery B, Almeida LMC, Mello SJ, et al. Extended-spectrum beta-lactamase-producing Klebsiella pneumoniae in a neonatal intensive care unit: risk factors for infection and colonization. J Hosp Infect. 2003;53(3):198-206.

17. Kermode M, Jolley D, Langkham B, Thomas MS, Holmes W, Gifford SM, et al. Compliance with universal/standard precautions among health care workers in rural north India. Am J Infect Control. 2005;33(1):27-33.

18. Chelenyane M, Endacott R. Self-reported infection control practices and perceptions of HIV/AIDS risk amongst emergency department nurses in Botswana. Accid Emerg Nurs. 2006;14(3):148-54.

19. Tenna A, Stenehjem EA, Margoles L, Kacha E, Blumberg HM, Kempker RR. Infection control knowledge, attitudes, and practices among healthcare workers in Addis Ababa, Ethiopia. Infect Control Hosp Epidemiol. 2013:34(12):1289-96.

20. Patarakul K, Tan-Khum A, Kanha S, Padungpean D, Jaichaiyapum 00 Cross-sectional survey of hand-hygiene compliance and attitudes of health care workers and visitors in the intensive care units at King Chulalongkorn Memorial Hospital. J Med Assoc Thai. 2005;88 Suppl 4:S287-93.

21. Sethi AK, Acher CW, Kirenga B, Mead S, Donskey CJ, Katamba A. Infection control knowledge, attitudes, and practices among healthcare workers at Mulago Hospital, Kampala, Uganda. Infect Control Hosp Epidemiol. 2012;33(9):917-23.

22. Amoran $\mathrm{O}$, Onwube $\mathrm{O}$. Infection control and practice of standard precautions among healthcare workers in northern Nigeria. J Glob Infect Dis. 2013;5(4):156-63.

23. $\mathrm{MOH}$. Infection control: policies and procedures. Uganda: Ministry of Health; 2005

24. $\mathrm{MOH}$. Uganda service provision assessment survey 2007. Ministry of Health and Macro International Inc. 2007. http://pdf.usaid.gov/pdf_docs/ PNADM577.pdf.

25. UBOS. The national housing and population census. Uganda: Ministry of Finance, Planning and Economic Development; 2002. http://www.ubos.org/ onlinefiles/uploads/ubos/pdf\%20documents/2002\%20Census\%20Final\% 20Reportdoc.pdf.

26. Kish LE. Survey sampling. New York: John Wiley and Sons; 1995

27. Pittet $D$, Donaldson L. Cost implications of successful hand hygiene promotion. Infect Control Hosp Epidemiol. 2004;25(3):264-6. 
28. Cochran WG, editor. Sampling techniques. 3rd ed. New York: John Wiley and Sons; 1977

29. Suchitra JB, Lakshmi DN. Impact of education on knowledge, attitudes and practices among various categories of health care workers on nosocomial infections. Indian J Med Microbiol. 2007;25(3):181-7.

30. WHO. Guidelines on hand hygiene in health care. First global patient safety challenge. Clean care is safer care. 2010. [Accessed on January 22, /2015] Available from: http://www.who.int/patientsafety/en/.

31. Pessoa-Silva CL, Meurer MB, Camara AV, Flannery B, Almeida LMC, Mello S, et al. Reduction of health care associated infection risk in neonates by successful hand hygiene promotion. Pediatrics. 2007;120(2):e382-90.

32. Hugonnet S, Pittet D. Hand hygiene-beliefs or science? Clin Microbiol Infect. 2000;6(7):350-6

33. Mazi W, Senok AC, Al-Kahldy S, Abdullah D. Implementation of the world health organization hand hygiene improvement strategy in critical care units. Antimicrob Resist Infect Control. 2013;2(1):15.

34. Erasmus V, Daha TJ, Brug H, Richardus JH, Behrendt MD, Vos M, et al. Systematic review of studies on compliance with hand hygiene guidelines in hospital care. Infect Control Hosp Epidemiol. 2010;31(3):283-94.

35. Caglar S, Yildiz S, Savaser S. Observation results of handwashing by health-care workers in a neonatal intensive care unit. Int J Nurs Pract. 2010;16(2):132-7.

36. Joshi S, Joshi A, Park BJ, Aryal UR. Hand washing practice among health care workers in a teaching hospital. J Nepal Health Res Counc. 2013;11(23):1-5

37. Pittet D, Mourouga P, Perneger TV. Compliance with handwashing in a teaching hospital. Infection control program. Ann Intern Med. 1999;130(2):126-30.

38. Pittet D, Hugonnet S, Harbarth S, Mourouga P, Sauvan V, Touveneau S, et al. Effectiveness of a hospital-wide programme to improve compliance with hand hygiene. Infection control programme. Lancet. 2000;356(9238):1307-12.

39. Askarian M, Mirzaei K, Honarvar B, Etminan M, Araujo MW, et al. Knowledge, attitude and practice towards droplet and airborne isolation precautions among dental health care professionals in Shiraz, Iran. J Public Health Dent. 2005;65(1):43-7.

40. CDC. Guidance for the selection and use of Personal Protective Equipment (PPE) in healthcare settings. 2010.

41. Sadoh WE, Fawole AO, Sadoh AE, Oladimeji AO, Sotiloye OS. Practice of universal precautions among healthcare workers. J Natl Med Assoc. 2006;98(5):722-6.

42. Samuel R, Almedom AM, Hagos G, Albin S, Mutungi A. Promotion of handwashing as a measure of quality of care and prevention of hospitalacquired infections in Eritrea: the Keren study. Afr Health Sci. 2005:5(1):4-13.

43. Farley JE, Tudor C, Mphahlele M, Franz K, Perrin NA, Dorman S, et al. A national infection control evaluation of drug-resistant tuberculosis hospitals in South Africa. Int J Tuberc Lung Dis. 2012;16(1):82-9.

44. Mbaisi EM, Ng'ang'a Z, Wanzala P, Omolo J. Prevalence and factors associated with percutaneous injuries and splash exposures among health-care workers in a provincial hospital, Kenya, 2010. Pan Afr Med J. 2013;14:10.

45. Abdella NM, Tefera MA, Eredie AE, Landers TF, Malefia YD, Alene KA. Hand hygiene compliance and associated factors among health care providers in Gondar University Hospital, Gondar, North West Ethiopia. BMC Public Health. 2014;14:96.

46. Rosenthal VD, Guzman S, Pezzotto SM, Crnich CJ. Effect of an infection control program using education and performance feedback on rates of intravascular device-associated bloodstream infections in intensive care units in Argentina. Am J Infect Control. 2003;31(7):405-9.

\section{Submit your next manuscript to BioMed Central and take full advantage of:}

- Convenient online submission

- Thorough peer review

- No space constraints or color figure charges

- Immediate publication on acceptance

- Inclusion in PubMed, CAS, Scopus and Google Scholar

- Research which is freely available for redistribution 